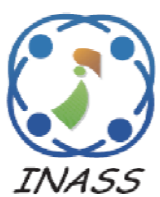

\title{
Combined Error Adaptive Fuzzy-PI for Reducing DC Voltage Ripple in Three- Phase SPWM Boost Rectifier Under Unbalanced DGs System
}

\author{
Dedy Kurnia Setiawan ${ }^{1,2}$ \\ Mochamad Ashari ${ }^{1 *}$ \\ Heri Suryoatmojo ${ }^{1}$ \\ ${ }^{I}$ Department of Electrical Engineering, Institut Teknologi Sepuluh Nopember, \\ Surabaya 60111, Indonesia \\ ${ }^{2}$ Department of Electrical Engineering, Universitas Jember, \\ Jember 68121, Indonesia \\ * Corresponding author's Email: ashari@ee.its.ac.id
}

Widya Cahyadi ${ }^{2}$

\begin{abstract}
Boost rectifiers are commonly used as the input for power inverters. The output voltage of the boost rectifiers should have high quality and precise value to enable the power inverters to achieve maximum performance. However, the grid occasionally supplied unbalanced voltage and current to the boost rectifiers so that the performance of the rectifiers is impaired. When unbalanced $\mathrm{AC}$ voltages occurred, the frequency of DC voltage ripples may become two times higher than the AC voltage frequency. The unbalance voltage and current may occur when the grid is supplied by several single-phase Distribution Generators (DGs) with varied capacities. This condition becomes more complicated if the DG is renewable energy in which the output power is intermittent. This study proposes a novel three-phase pulse-width modulated (PWM) boost rectifier control using Voltage Oriented Control (VOC) with a Combined error adaptive fuzzy-PI (CEAF). CEAF is a combination of the Delta error adaptive fuzzy (DEAF) and the Absolute error adaptive fuzzy (AEAF). DEAF is a self-tuning fuzzy-PI method that is generally used as an adaptive fuzzy controller with inputs of errors e $(t)$ and delta error de $(t)$. As for AEAF, it is a modified DEAF of which the inputs are the absolute values of e(t) and de(t). This adaptive Fuzzy-PI is used to determine $K_{p}$ and $K_{i}$ values that suit the needs, especially when the sources are fluctuating or unbalanced. The performance of the proposed controller is then compared with a conventional DEAF and with a well-adjusted PI controller. Based on the simulation in Matlab/Simulink, the proposed method would result in a significant reduction in DC voltage ripples and DC steadystate error when fluctuating, unbalanced voltages occur. The resulted ripple voltage decreases from $0.16 \%$ to become $0.12 \%$. The steady-state error decreases from $0.27 \%$ to become $0.19 \%$.
\end{abstract}

Keywords: Adaptive fuzzy-PI, Boost rectifier, Combined error adaptive fuzzy, Delta error adaptive fuzzy, Distributed generation, Voltage oriented control, Weak grid.

\section{Introduction}

The application of Distributed Generators (DG) has been increasing rapidly in recent years, due to the development of renewable energy technologies, especially wind turbines and photovoltaics. DGs can have essential roles in supporting electric power systems. DGs improving power quality and reducing transmission and distribution costs[1-3]. On the other hand, solar and wind energy are intermittent because of natural conditions. Therefore, DGs based on solar and wind energy sources cannot always provide steady support to the distribution system.
Most traditional distribution systems have not been designed to well suit the DGs penetration. Therefore, high DGs penetration can raise problems in the distribution network, especially when the DGs connected to the network have varied capacities and types. A common problem is the unbalance in voltage and current. This unbalance causes adverse effects on electrical distribution systems and electronic equipment, such as rectifiers [4-8].

Three-phase boost rectifiers under ideal grid voltages shown in Fig. 1, can achieve constant DC voltage, a high power factor, and sinusoidal grid currents at the input side. 


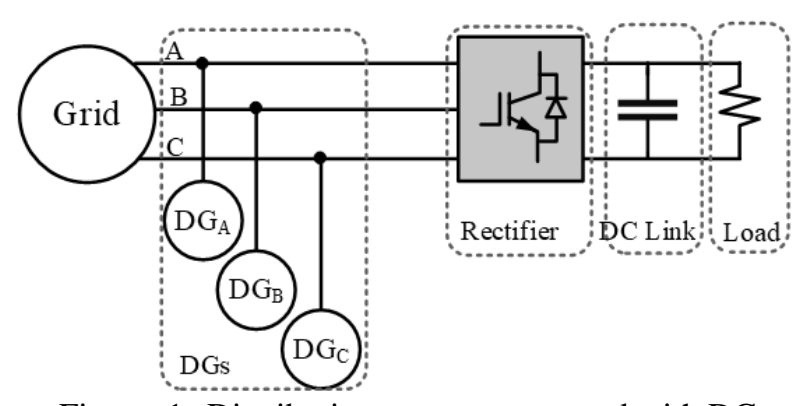

Figure. 1 Distribution system connected with DGs

Several studies have proposed various control methods for controlling rectifiers such as direct power control (DPC) and voltage oriented control (VOC) [5, 9-14]. However, when the sources are unbalanced, control methods developed under balanced conditions are not effective. The grid currents will be strongly distorted. There will be oscillations or ripples in the DC bus voltages with high frequency, sometimes two times higher than the grid frequency [5]. DC voltage ripples emerge due to regular charging and discharging of capacitors, hence high-frequency currents would affect the life of the capacitors. The use of larger capacitance of the capacitors can reduce the DC voltage ripples [11], [15]. However, it is not cost-effective and it increases the weight and size of the equipment. Therefore, the development of power control methods in unbalanced network conditions has become an important topic in recent years.

DPC has recently been extended to control unbalanced grid voltage rectifiers. However, this method has the following disadvantages [16]:

1. The complexity of the control increases due to the need to calculate power compensation and to extract voltage and current into positive-negative sequences

2. The high sampling frequency is required because estimated values over time are not constant,

3. High inductance is needed due to the everchanging switching frequency.

4. Difficulties in designing input filters and power calculations during switching (errors) happen due to the non-constant switching frequency.

In contrast to DPC, VOC offers several advantages, including low sampling frequency for better performance and constant switching frequency that makes filter input design easier. However, in the classical VOC, voltage and current in a synchronous reference frame $(d q)$ are controlled using a proportional-integral controller (PI). It is possible to achieve good steady-state output and fast dynamic response in VOC, but it requires a proper PI adjustment, especially if the sources are unbalanced and fluctuating as in DGs $[16,17]$.
The rectifier system proposed in this study is designed to use the adaptive fuzzy PI controller to avoid the PI tuning in changing conditions, especially during transients. A fuzzy logic control has benefits over a PI control because the former does not need a mathematical model whereas the former does. In addition, the former can operate better on non-linear systems than the latter. Some studies have used an adaptive fuzzy controller to control the rectifier. The method generally uses the error signal (e) and delta error signal (de) as input signals to determine the proportional constants of PI $(K p)$ and integral constants $(K i)$. In this paper, this adaptive controller is namely Delta error adaptive fuzzy (DEAF) [18-22].

Combined error adaptive fuzzy (CEAF) is a novel adaptive fuzzy method suggested in this study. CEAF is using a combination of two modified DEAFs. Each of DEAFs is responsible for determining the value of $K p$ and $K i$ independently. The response of the system equipped with the proposed controller to transient operations (start, reference changes, and DG supply changes) is observed and compared to the response of the system equipped with previous self-tuning fuzzyPI control methods, DEAF, and the conventional PI controllers to check the effectiveness of the proposed controllers.

This paper is organized as follows: Section 2 presents our proposed method. Section 3 describes the design of optimization and control. Section 4 describes the results of the investigation and simulation. Finally, in Section 5, we present conclusions.

\section{System description and modeling}

The boost rectifier scheme under study is shown in Fig. 2. A series of filters consisting of inductances, $\mathrm{L}$, and resistances, $\mathrm{R}$, connect the rectifier to the network. $e_{a}, e_{b}$, and $e_{c}$ are source voltages, while the input currents are $i_{a}, i_{b}$, and $i_{c}$, respectively. Each phase's terminal voltages are $v_{a n}, v_{b n}$, and $v_{c n}$, respectively. $V_{d c}, \mathrm{C}$, and $R$ are dc-link voltages, capacitance of the capacitor, and the load $[16,17]$.

Based on Fig. 2, the average three-phase rectifier model can be described as shown in (1) in the abc coordinates.

$$
L \frac{d}{d t}\left[\begin{array}{l}
i_{a} \\
i_{b} \\
i_{c}
\end{array}\right]=\left[\begin{array}{ccc}
-R & 0 & 0 \\
0 & -R & 0 \\
0 & 0 & -R
\end{array}\right]\left[\begin{array}{l}
i_{a} \\
i_{b} \\
i_{c}
\end{array}\right]+\left[\begin{array}{l}
e_{a}-v_{a n} \\
e_{b}-v_{b n} \\
e_{c}-v_{c n}
\end{array}\right]
$$

and, the DC capacitor voltage is:

$$
C \frac{d V_{d c}}{d t}=\frac{1}{2}\left(\beta_{a} i_{a}+\beta_{b} i_{b}+\beta_{c} i_{c}\right)-\frac{V_{d c}}{R_{L}}
$$


where

$$
\left[\begin{array}{l}
v_{a n} \\
v_{b n} \\
v_{c n}
\end{array}\right]=\frac{V_{d c}}{6}\left[\begin{array}{ccc}
2 & -1 & -1 \\
-1 & 2 & -1 \\
-1 & -1 & 2
\end{array}\right]\left[\begin{array}{l}
\beta_{a} \\
\beta_{b} \\
\beta_{c}
\end{array}\right]
$$

Using the Park transformation, the rectifier model in Eqs. (1) and (2) can be represented in the synchronous $d q$ frame Eq. (3).

$$
\left[\begin{array}{l}
e_{d} \\
e_{q}
\end{array}\right]=L \frac{d}{d t}\left[\begin{array}{l}
i_{d} \\
i_{q}
\end{array}\right]+\left[\begin{array}{cc}
R & -\omega L \\
\omega L & R
\end{array}\right]\left[\begin{array}{l}
i_{d} \\
i_{q}
\end{array}\right]+\left[\begin{array}{l}
v_{d n} \\
v_{q n}
\end{array}\right]
$$

where $e_{d}, e_{q}, i_{d}$, and $i_{q}$ are the input voltages and input currents of the rectifier, respectively, while $v_{d n}$ and $v_{q n}$ are the terminal voltages of the rectifier.

The dynamics of the DC output rectifier can be expressed through Eq. (4), where $\beta_{d}$ and $\beta_{q}$ are the modulation signals.

$$
C \frac{d V_{d c}}{d t}+\frac{V_{d c}}{R_{L}}=\frac{3}{4}\left(\beta_{d} i_{d}+\beta_{q} i_{q}\right)
$$

The power value on the rectifier, both the active power, $\mathrm{P}$, and the reactive power, $\mathrm{Q}$, are determined as Eqs. (5) and (6).

$$
\begin{aligned}
& P=\frac{3}{2}\left(e_{d} i_{d}+e_{q} i_{q}\right) \\
& Q=\frac{3}{2}\left(e_{d} i_{d}-e_{q} i_{q}\right)
\end{aligned}
$$

By changing the d-axis vector of the network voltage (e.g. $E_{d}=E$ and $e_{q}=0$ ), Eqs. (5) and (6) becomes Eq. (7).

$$
P=\frac{3}{2} E i_{d} ; Q=\frac{3}{2} E i_{d}
$$

For control purposes and grid synchronization, each of DC link voltage, input voltage, and input current are equipped with sensors. The control system used is a two-part VOC, namely: DC voltage regulator and current regulator, as shown in Fig. 3.

\subsection{DC voltage regulator}

To be able to generate a DC output voltage with a minimum ripple, $i_{d} *$ is needed to be adjusted when changing the system and the reference output voltage. For this reason, a voltage regulator with a circuit scheme is needed, as shown in Fig. 4. This figure shows the relationship between the values of $K i$ and $K p$, as shown in Eq. (8).

$$
i_{d}^{*}=K_{p v}\left(V_{d c}^{*}-V_{d c}\right)+\int K_{i v}\left(V_{d c}^{*}-V_{d c}\right) d t
$$




\subsection{Current regulator}

It is not recommended to use a PI controller to control the boost rectifier for a system that is coupled, as shown in Eq. (3) because when a variable changes, the other variables will also change. They can not control themselves independently. The feedforward decoupling control must be run to be independently controlled using the PI controller. This is shown in Eq. (9), where $K_{p c}$ and $K_{i c}$ are, respectively, proportional and integral gains of the PI controllers.

$$
K_{p c}\left(i_{q}^{*}-i_{q}\right)+\int K_{i c}\left(i_{q}^{*}-i_{q}\right) d t=L \frac{d i_{q}}{d t}+R i_{q}
$$

Upon decoupling, $i_{d}$ and $i_{q}$ values can be managed separately. Thus, changes in the value of active and reactive power can also be independently controlled. This can make the design of the current controller much easier with the control principle presented in Fig. 5.

The current regulator output signal is used to control switching semiconductors of boost rectifiers through SPWM. The signal is compared to the carrier signal, a triangular signal, to obtain a sequence of pulses. The resulting pulses are channeled into the switching circuit. $S a, S b$, and $S c$ stand for the switching state of each phase leg.

\subsection{Phase-locked loop (PLL)}

During the control of the boost rectifier, VOC uses the signal in dq reference frame. A three-phase synchronous reference frame loop-locked (SRFPLL) is used in this paper to transform abc to dq and synchronize the boost rectifier.

SRF-PLL will approximate the network voltage phase and the output is the cosine and sine signal. To preserve the value of $v_{q}$ to 0 , PI controller is used. Thus, the phase can be effectively locked. Fig. 6 illustrates the SRF-PLL control theory [23, 24].

The advantage of using SRF-PLL relative to other PLLs is that it is simple to implement so that it can conserve digital resources and processing time.

\subsection{Limitation}

Based on Fig. 2, the minimum DC-link voltage is required if the boost rectifier is to operate appropriately and generate an undistorted current waveform output. In addition, the maximum DC output voltage value for rectifiers that use diode bridge circuits is line-to-line RMS voltage [16, 17]. The DC-link voltage, on the other hand, depends on the use of the chosen PWM system.

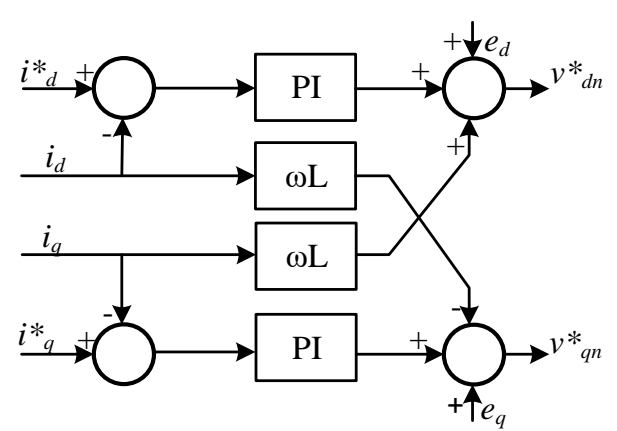

Figure. 5 Decoupled VOC currents regulator of threephase rectifier

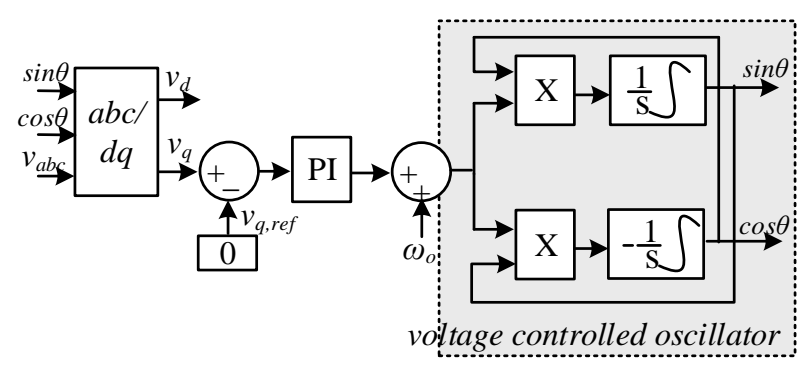

Figure. 6 SRF-PLL structure

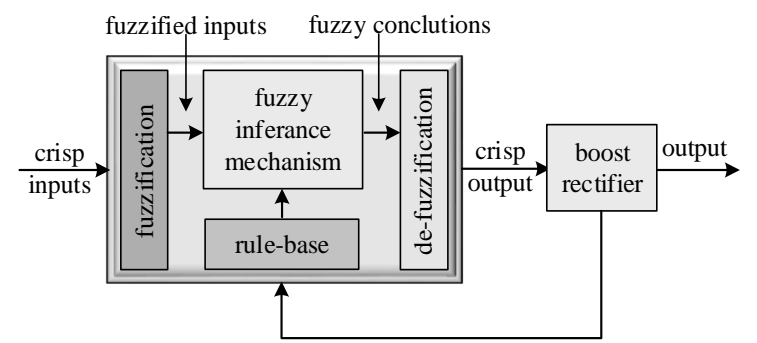

Figure. 7 The main section of FLC for boost rectifier

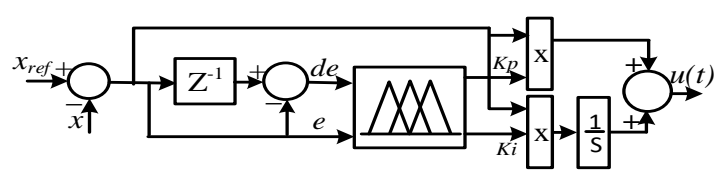

Figure. 8 Structure of DEAF

SPWM with maximum $V d c / 2$ reference voltage is used in this article. The minimum voltage of DC-link can, therefore, be specified as Eq. (10).

$$
V_{d c}>2 V_{L N(\text { peak })}=\frac{V_{L L(r m s)}}{\sqrt{3}} 2 \sqrt{2}
$$

The minimum value of DC-link voltage, according to Kasmierkowski, is also determined by the value of the channel inductance. The DC-link voltage increases when the line impedance is increased. This value is expressed as Eq. (11). This formula ignores the value of the line resistance.

$$
V_{d c}>\sqrt{3\left(E_{m}^{2}+\left(\omega L i_{d}\right)^{2}\right)}
$$


From this equation, we can get the maximum inductance value as

$$
L=\sqrt{\frac{V_{d c}^{2}}{3}-E_{m}^{2}} / \omega i_{d}
$$

\section{Ripple minimization control}

For some applications, a precise output voltage of a boost-rectifier is required. The difference in value affects equipment performance which uses a rectifier as a source of electricity, although the order is millivolt.

In situations of unbalanced network voltage and current due to DG fluctuations, special attention needs to be paid to the boost rectifier to operate properly. The boost rectifier operation depends on the control circuit structure being implemented. It also depends on the implemented control algorithm. The control algorithm, which works at unbalanced voltage changes, will encounter the following problems: DC-link oscillation, an unstable power factor, and three-phase current distortion.

It can be determined through the ripple ratio to find out the value of the voltage ripple. Ripple ratio $\left(R_{v}\right)$ can be defined as the ratio of ripple amplitude $\Delta V_{p p}$ (peak to peak) to the mean voltage $V_{a}$, shown in (13) [25].

$$
R_{v}=\frac{\Delta V_{p p}}{V_{a}} 100 \%
$$

\subsection{PI controller}

Both of voltage regulator and current regulator in VOC are configured with PI controllers for excellent performance of DC voltage control. The primary function of a boost rectifier voltage regulator is to control the voltage of the DC-link and generate a current reference ID for the current regulator. To ensure the unity power factor, the reactive power of the voltage regulator must equal zero. Fig. 4 and Fig. 5 displays a voltage regulator and current regulators based on PI controllers.

Nevertheless, when the voltage and the current of the sources are unbalanced due to fluctuations in DGs, the parameters of $K_{p}$ and $K_{i}$ in each regulator must be re-tuned so that the PI controller can function properly.

\subsection{Adaptive fuzzy controller}

An adaptive controller is required to overcome the weakness of the PI controller in anticipating changes in the fluctuation of the boost rectifier source.
This study proposes to modify the use of the conventional PI by applying fuzzy logic. By applying fuzzy logic, the values of $K_{p}$ and $K_{i}$ need not be modified every time a change occurs. The controller is flexible with the use of a fuzzy logic controller (FLC) in adaptive Fuzzy-PI so that the system achieves high precision and good performance [19, 26, 27].

The advantage of an FLC over a PI controller is that FLC enables the inclusion of human deductive thinking in the control system. It makes the dependency on mathematical models is significantly reduced. Besides, FLC is also capable of controlling complex, nonlinear systems.

The structure of the FLC typically consists of four main sections, namely: fuzzification, rule-base, system of inference, and defuzzification, as shown in Fig. 8.

1. Fuzzification is a system input interface that uses fuzzy linguistic variables and membership functions to transform real data (crisp) into fuzzy sets.

2. Rule-base is a set of fuzzy IF-THEN rules that includes the premises and implications. These rules specify the behavior of the controller based on the conditions of the input.

3. Fuzzy inference system is related to the decisionmaking process for the implementation of rule bases. Mamdani system is used in the adaptive fuzzy system proposed in this study. This inference has fast response time and simplicity.

4. Defuzzification is the last step that is used to transform fuzzy inference results in an output that can be expressed in crisp logic. In other words, the defuzzification is the reverse process of the fuzzification. This step results in the most certain controller action.

The membership function and rule-base are vital to the process of fuzzification and defuzzification, especially for the performance of fuzzy control techniques.

We propose to use combined error adaptive fuzzy (CEAF) controller. This adaptive fuzzy-PI controller is used in both of current regulator and voltage regulators as shown in Fig. 7. Therefore, to effectively demonstrate the proposed boost-rectifier control strategy in minimizing the ripple voltage compared to the previous self-tuning method of selftuning, delta fuzzy error (DEAF).

\section{A. Delta Error Adaptive Fuzzy (DEAF)}

DEAF is a self-tuning fuzzy method which is commonly used as a controller [18-22]. In recent engineering research, DEAF is used to optimize the 
flux distribution of dual parabolic dish concentrates using a robotic arm system [28]. In this paper, two inputs and two outputs are used. The first input is error e $(\mathrm{t})$; it is the difference between the reference value and the measured value, either of voltage or current. The DC voltage error in Eq. (13) is the fuzzy input in the voltage regulator. As for the current regulator, as shown in Fig. 8, the two DEAFs used with error $(e)$ input variables are the current $i_{d}$ and $i_{q}$.

$$
\begin{aligned}
& e_{1}(k)=v_{d c, r e f}-v_{d c}(k) \\
& e_{2}(k)=i_{d, r e f}-i_{d}(k) \\
& e_{3}(k)=i_{q, r e f}-i_{q}(k)
\end{aligned}
$$

where $k$ is the actual discrete-time, $i_{d} i_{q}$ are the actual currents in $d q$ reference frame, and $i_{d, \text { ref }} i_{q, \text { ref }}$ are the reference currents.

The second input for both regulators is delta error (de), derived from the difference in error with the previous error input, as shown in Fig. 9 and Eqs. (17) and (18).

$$
\begin{aligned}
& d e_{2}(k)=e_{2}(k)-e_{2}(k-1) \\
& d e_{3}(k)=e_{3}(k)-e_{3}(k-1)
\end{aligned}
$$

For each input and output, the fuzzy DEAF membership function is given as follows: membership functions for $e(k)$ and $d e(k)$ are defined in five functions using "trimf" type, defined as negative large (NL), negative small (NS), zero (Z), positive small (PS), and positive large (PL), as shown in Fig. 9. Meanwhile, for the output values of $K_{p}(k)$ and $K_{i}(k)$, the five membership functions are defined as zero (Z), positive small (PS), positive medium $(\mathrm{PM})$, positive large (PL), and positive very large (PVL), as shown in Fig. 10.

The rule-bases on voltage and current regulators are designed and given in Table 1 for $K p$ and Table 2 for the rule base of $K i$. Every couple of error and delta error change inputs triggers one rule.

Table 1. Rule base of $K p$ using DEAF

\begin{tabular}{|c|ccccc|}
\hline \multirow{2}{*}{$\mathrm{e}$} & \multicolumn{5}{|c|}{ de } \\
\cline { 2 - 6 } & NB & NS & Z & PS & PB \\
\hline NB & PVB & PB & PM & PS & ZE \\
NS & PB & PM & PS & ZE & PS \\
Z & PM & PS & ZE & PS & PVB \\
PS & PS & ZE & PS & PVB & PB \\
PB & ZE & PS & PVB & PB & PM \\
\hline
\end{tabular}

Table 2. Rule base of $K i$ using DEAF

\begin{tabular}{|c|ccccc|}
\hline \multirow{2}{*}{$\mathrm{e}$} & \multicolumn{5}{|c|}{ de } \\
\cline { 2 - 6 } & NB & NS & Z & PS & PB \\
\hline NB & PM & PB & PVB & PS & ZE \\
NS & PB & PVB & PS & ZE & PS \\
Z & PVB & PS & ZE & PS & PM \\
PS & PS & ZE & PS & PM & PB \\
PB & ZE & PS & PM & PB & PVB \\
\hline
\end{tabular}

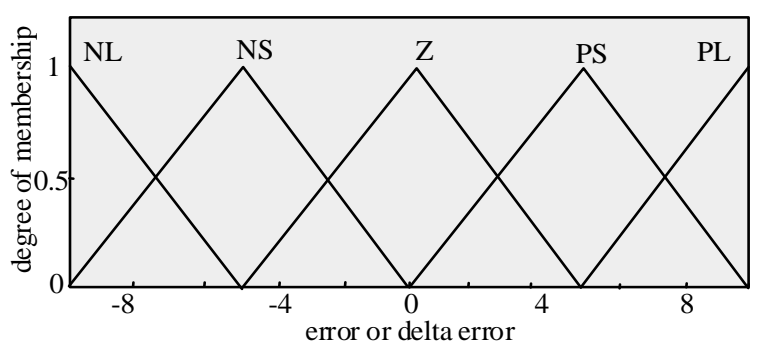

Figure. 9 Membership function of DEAF input: e and de

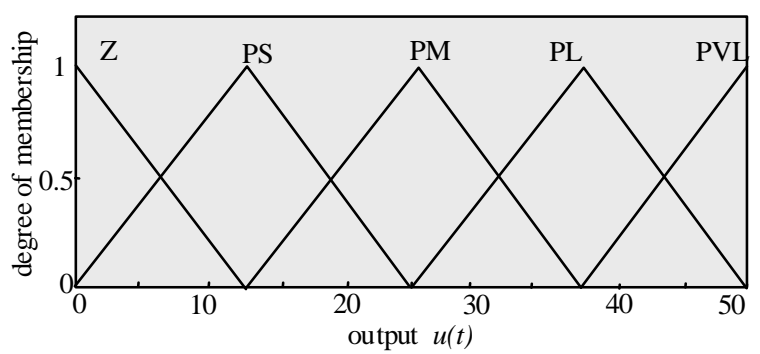

Figure. 10 Membership function of DEAF output: $K p$ and $K i$

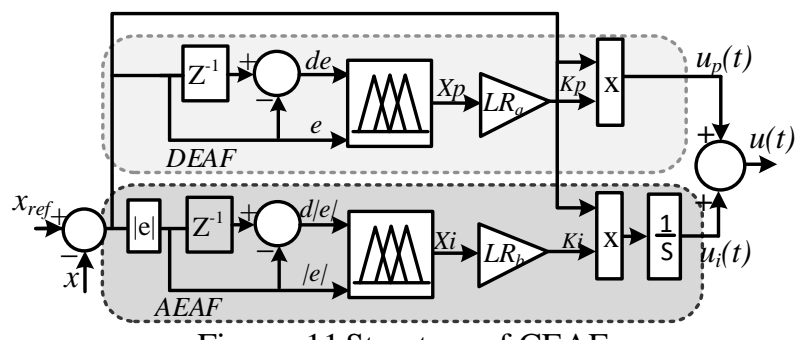

Figure. 11 Structure of CEAF

\section{B. Combined Error Adaptive Fuzzy (CEAF)}

CEAF combines DEAF and absolute error adaptive fuzzy (AEAF). CEAF is thus expected to produce better and more accurate performance than the previous method. Every adaptive fuzzy is responsible for the constant PI. To regulate $K p$ controller uses DEAF, while AEAF regulates the $K i$ with absolute error input values, shown in Fig. 11 and Fig. 12.

The absolute error is the absolute difference between the reference voltage and the measured voltage for the voltage regulator. For the current regulator, absolute error is an absolute difference between the reference current and the measured 


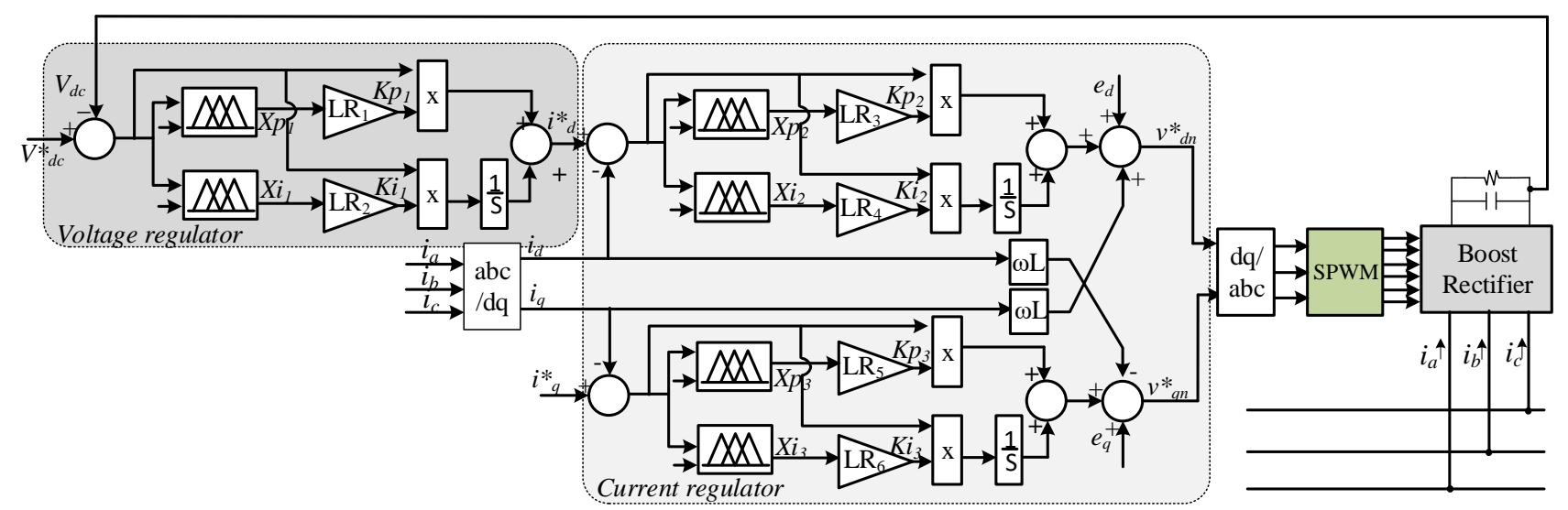

Figure. 12 VOC method for boost rectifier on CEAF-PI controller

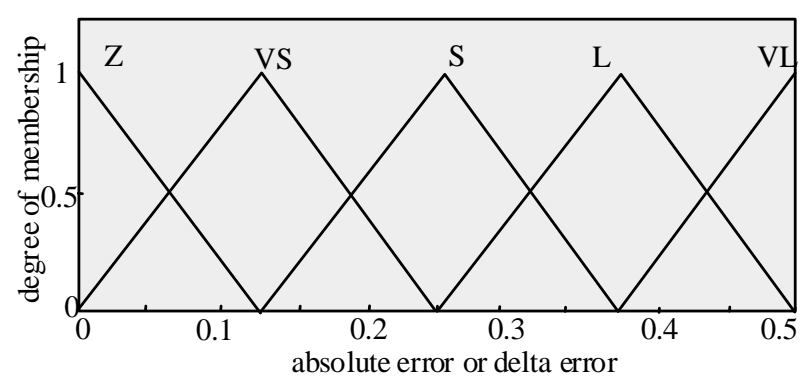

Figure. 13 Membership function of AEAF input $|e|$ and $\mathrm{d}|e|$

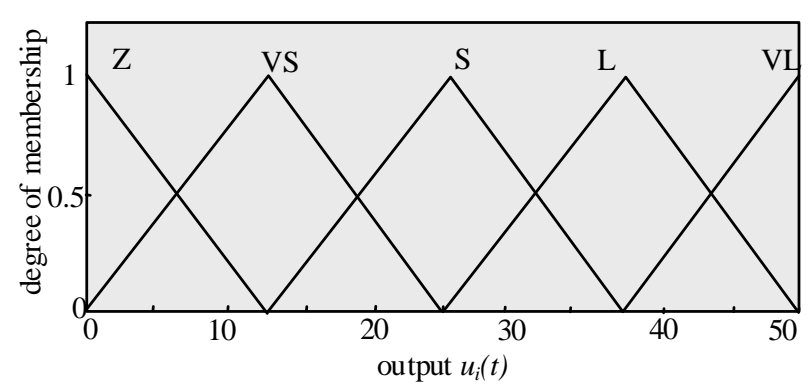

Figure. 14 The membership function of AEAF output $K i$

Table 3. Rule base of $K i$ using AEAF

\begin{tabular}{|c|ccccc|}
\hline \multirow{2}{*}{$\mathrm{e}$} & \multicolumn{5}{|c|}{ de } \\
\cline { 2 - 6 } & $\mathrm{Z}$ & $\mathrm{VS}$ & $\mathrm{S}$ & $\mathrm{L}$ & $\mathrm{VL}$ \\
\hline $\mathrm{Z}$ & $\mathrm{Z}$ & $\mathrm{Z}$ & $\mathrm{Z}$ & $\mathrm{VS}$ & $\mathrm{VS}$ \\
$\mathrm{VS}$ & $\mathrm{VS}$ & $\mathrm{VS}$ & $\mathrm{VS}$ & $\mathrm{S}$ & $\mathrm{S}$ \\
$\mathrm{S}$ & $\mathrm{S}$ & $\mathrm{S}$ & $\mathrm{S}$ & $\mathrm{L}$ & $\mathrm{L}$ \\
$\mathrm{L}$ & $\mathrm{L}$ & $\mathrm{L}$ & $\mathrm{L}$ & $\mathrm{L}$ & $\mathrm{VL}$ \\
$\mathrm{VL}$ & $\mathrm{VL}$ & $\mathrm{VL}$ & $\mathrm{VL}$ & $\mathrm{VL}$ & $\mathrm{VL}$ \\
\hline
\end{tabular}

current. For membership functions and rule-based DEAF in CEAF, it uses the same values shown in Fig.9, Fig.10, and Table 1.

Based on Fig. 11, a CAEF controller can be mathematically expressed as:

$$
u(t)=u_{p}(t)+u_{i}(t)
$$

$$
u(t)=X_{p} L R_{a} e(t)+X_{i} L R_{b} \int e(t) d t
$$

where $X_{p}$ and $X_{i}$ are the output of the CEAF controller and $L R_{a}(\mathrm{a}=1,3,5)$ and $L R_{b}(\mathrm{~b}=2,4,6)$ are learning rate constants for $K_{p}$ and $K_{i}$ respectively, as shown in Figs. 11 and 12 .

AEAF membership function sets for input and output are defined as zero (Z), very small (VS), small $(\mathrm{S})$, large (L), and very large (VL), as displayed in Figs. 13 and 14.

The triangle membership function was used on this fuzzy control. It used to compare the current or voltage value fluctuation which has a high value variance. The advantage was that it could detect a slight fluctuation in current or voltage and suggested an accurate and fast decision for the boost rectifier control process.

Table 3 displays the matrix of fuzzy AEAF rules which is based on the dynamic behavior of the error signal. These rules have been defined.

\section{Simulation results and discussion}

The proposed adaptive fuzzy was tested using the SPWM boost rectifier shown in Fig. 12 under balanced and unbalanced network conditions.

Single-phase DG with various capacities triggers an unbalanced grid. The voltage/current probe is used to measure the grid voltage, grid current, and DC bus voltage during the test. Table 4 lists the system and control parameters used in this paper, where the sampling time for Ts is $100 \mu \mathrm{s}$.

\subsection{Balanced grid network}

In balanced conditions, the grid and DG bus deliver equal power for each phase. The grid capacity is $200 \mathrm{kVA}$, and the DG sends power $20 \mathrm{~kW}$ for each phase. 
Table 4. Parameters of boost rectifier and DGs system

\begin{tabular}{|c|c|c|}
\hline \multicolumn{2}{|c|}{ Parameters } & Value \\
\hline \multirow{3}{*}{ Rectifier } & $\begin{array}{l}\text { Rated output voltage } \\
\left(V_{D C}\right)\end{array}$ & $700 \mathrm{~V}$ \\
\hline & $\begin{array}{l}\text { Rated input voltage }\left(V_{A N},\right. \\
\left.V_{B N}, V_{C N}\right)\end{array}$ & $220 \mathrm{~V}$ \\
\hline & Input frequency & $50 \mathrm{~Hz}$ \\
\hline \multirow{2}{*}{ Filter } & Inductance $\left(L_{f},\right)$ & $0.3 \mathrm{mH}$ \\
\hline & Resistance $\left(R_{f}\right)$ & 0.1 \\
\hline \multirow{2}{*}{ DG bus } & Rated input voltage $\left(V_{D G}\right)$ & 220 \\
\hline & Rated power $(\mathrm{A}, \mathrm{B}, \mathrm{C})$ & fluctuating \\
\hline \multirow{3}{*}{ Grid } & $\begin{array}{l}\text { Rated output voltage }\left(V_{A N},\right. \\
\left.V_{B N,}, V_{C N}\right)\end{array}$ & $220 \mathrm{~V}$ \\
\hline & Frequency & $50 \mathrm{~Hz}$ \\
\hline & Rated power (3phase) & $200 \mathrm{KVA}$ \\
\hline
\end{tabular}

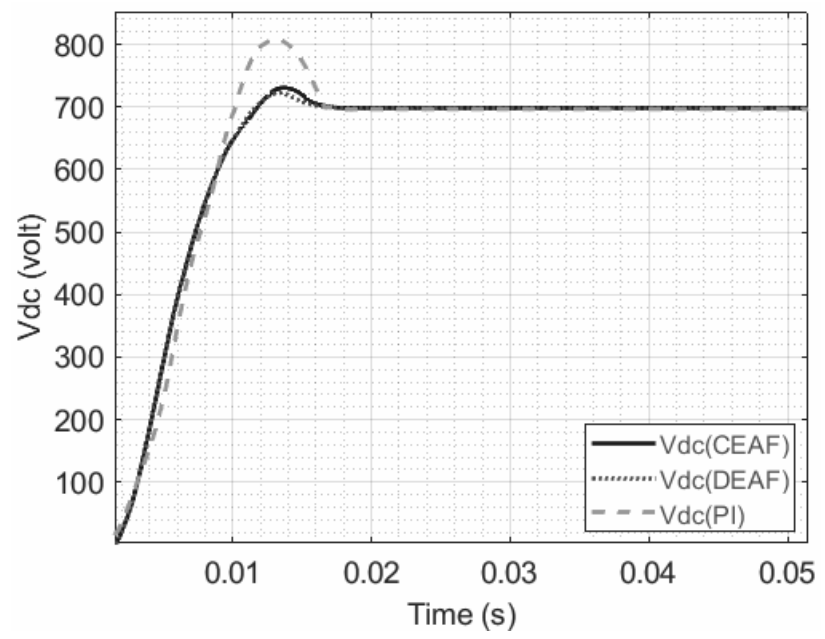

Figure. 15 DC voltage output under balanced grid/DG

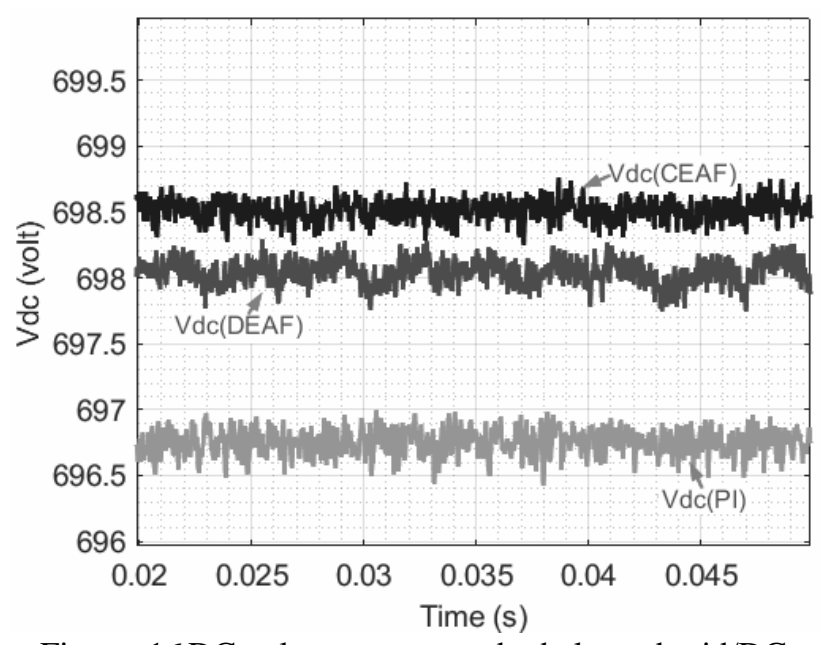

Figure. 16 DC voltage output under balanced grid/DG

Source voltage and source current of the boost rectifier is shown in Fig. 15. The boost rectifier with the PI controller has the highest overshoot during the transient phase at initialization, which is 850 volts. While overshooting is relatively the same for both adaptive fuzzy which is equal to 750 Volts.

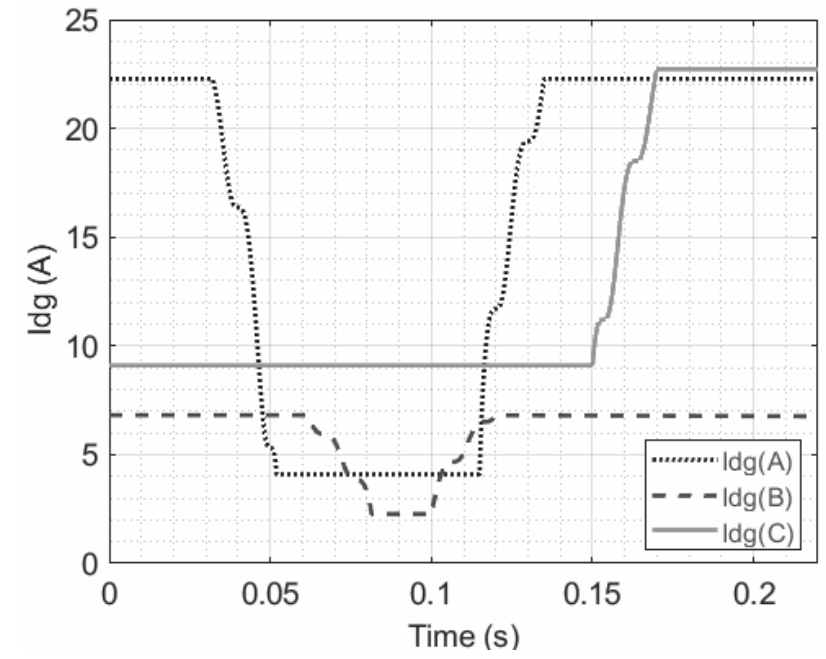

Figure. 17 Current injection from DG bus

Table 5. DC voltage under balanced grid condition

\begin{tabular}{|l|l|l|l|l|c|}
\hline \multirow{2}{*}{} & \multicolumn{3}{|c|}{ Voltage (volt) } & \multirow{2}{*}{$\begin{array}{c}\text { Ripple } \\
(\%)\end{array}$} & $\begin{array}{c}\text { Steady- } \\
\text { state } \\
\text { error } \\
(\%)\end{array}$ \\
\cline { 2 - 4 } & $\max$ & min & mean & & 0.47 \\
\hline PI & 696.42 & 696.99 & 696.74 & 0.08 & 0.47 \\
\hline DEAF & 697.74 & 698.28 & 698.04 & 0.08 & 0.28 \\
\hline CEAF & 698.25 & 698.76 & 698.51 & 0.07 & 0.21 \\
\hline
\end{tabular}

The average DC voltage of three controllers tends to be the same under steady-state conditions. If those outputs are zoomed, however, the graph will become Fig. 16. CEAF's maximum steady-state output voltage is 698.6 volts whereas it is 698.1 volts and 696.8 volts for DEAF and PI controllers respectively.

The ripple ratio of the output voltage is measured with (13). The values of ripple voltages and steadystate errors of the controllers under balanced grid conditions are shown in Table 5.

Table 5 describes the comparison of the DC voltages as well as the ripples and steady-state errors of three control methods, namely PI, CEAF, and DEAF under balanced conditions. This table shows that the use of CEAF produced the lowest ripple voltage and steady state error.

\subsection{Unbalanced grid}

The DG deliver power to the grid with the following scenario:

1. on the initial conditions, the DG system inject 4.9 $\mathrm{kW}, 1.5 \mathrm{~kW}$ and $3 \mathrm{~kW}$ respectively for phase $\mathrm{A}$, $\mathrm{B}$, and $\mathrm{C}$

2. when time $t=0.030$ seconds: $D G$ injected at phase A decreased at to $0.9 \mathrm{~kW}$

3. when time $t=0.060$ seconds: $\mathrm{DG}$ on phase $\mathrm{B}$ decrease from $1.5 \mathrm{~kW}$ to $1 \mathrm{~kW}$ 


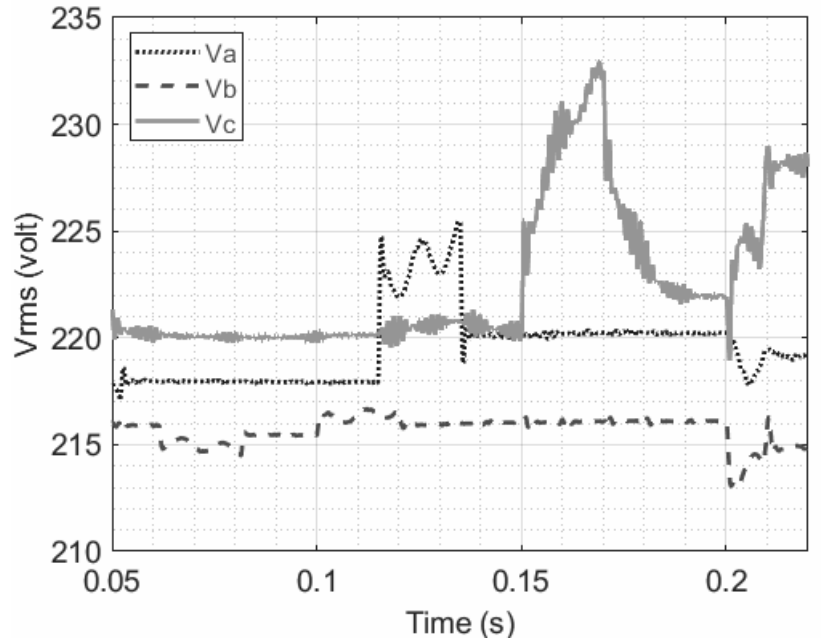

(a)

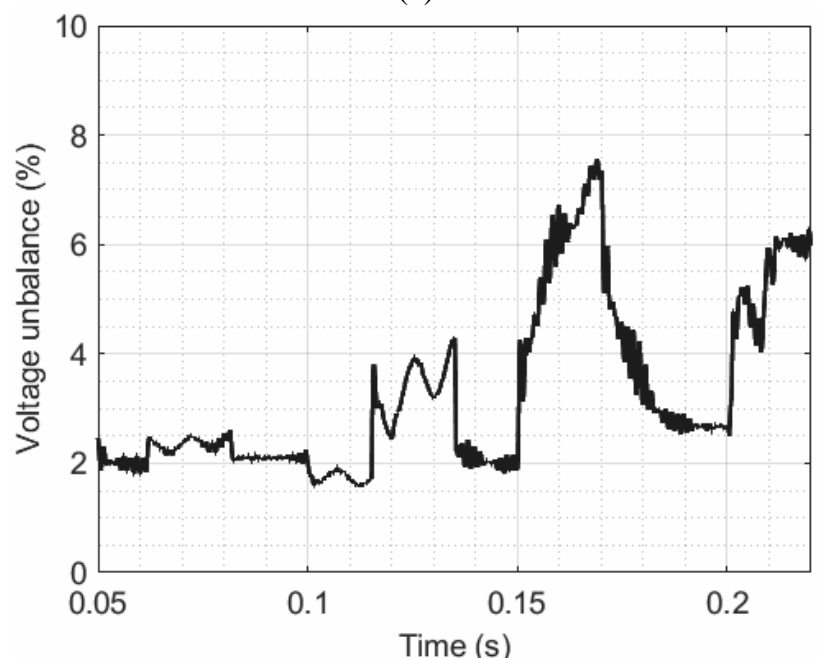

(b)

Figure. 18 Grid voltage under fluctuating unbalanced DG : (a) rms value, (b) unbalance

4. when time $t=0.10$ seconds: $D G$ on phase $B$ become to initial condition, $1.5 \mathrm{~kW}$

5. when time $\mathrm{t}=0.115$ seconds: $4 \mathrm{~kW}$ DG reinjected current to phase $\mathrm{A}$

6. when time $\mathrm{t}=0.150$ seconds: $2 \mathrm{~kW}$ DG on phase C connected

7. at $\mathrm{t}=0.200$ seconds: the DC voltage reference changed from 700 volts to 800 volts

The plot in Fig. 17 shows the behavior of the current injected to the distribution network from the DG bus. The fluctuation of the supplied power, which is delivered by the DGs under the aforementioned scenario, results in the grid voltage and grid current profiles shown in Fig.18 and Fig.19, respectively.

Because of the fluctuating current injection, both the grid voltage and the grid current become fluctuating and unbalanced, as seen at the timesteps of $0.150 \mathrm{~s}$ to $0.200 \mathrm{~s}$ when the C-phase current of the DG increased from 9 A to 22 A (see Fig 17). Due to this increase, the transient grid voltage and current

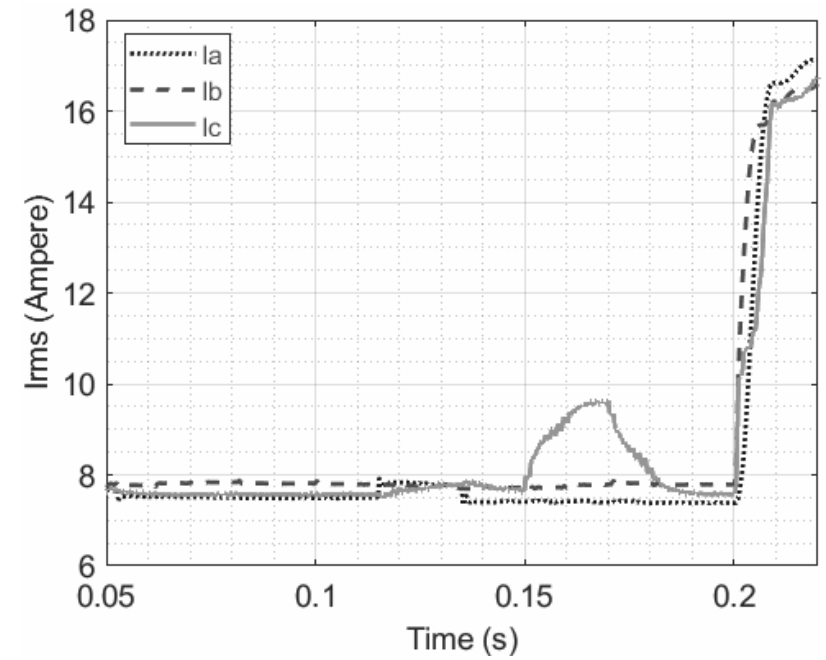

(a)

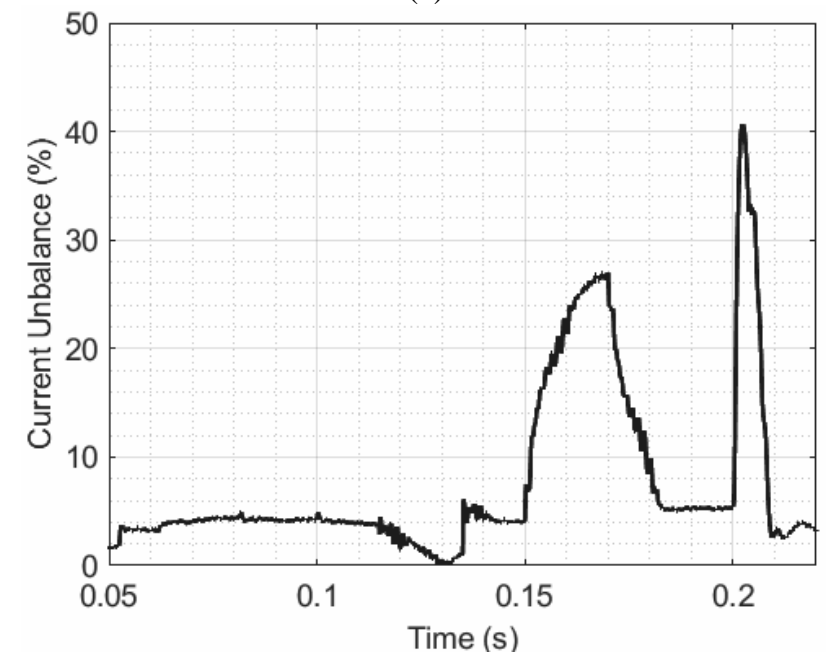

(b)

Figure. 19 Grid current under fluctuating unbalanced DG:

(a) rms value and (b) unbalance

increased sharply before steady-state, as seen in Fig 18 and Fig 19). The voltage unbalance rose from 5\% to $14 \%$ and then gradually decreased from $14 \%$ to $10 \%$, whereas the current unbalance jumped from $2 \%$ to $31 \%$, and then decreased gradually to about $2 \%$ again.

The changes in voltages and currents in the distribution system follows the change in DGs. This situation can happen in a weak distribution system. The changes in the current and the voltage in each phase result in a change of the extent of the unbalance. The extent of the voltage and current unbalance is determined based on the ANSI / IEEE Std 241-1990.

The performance of the proposed controller is observed in two conditions, namely in the transient and the dynamic condition.

\section{A. Transient Condition}

The transient condition in this study occurs 


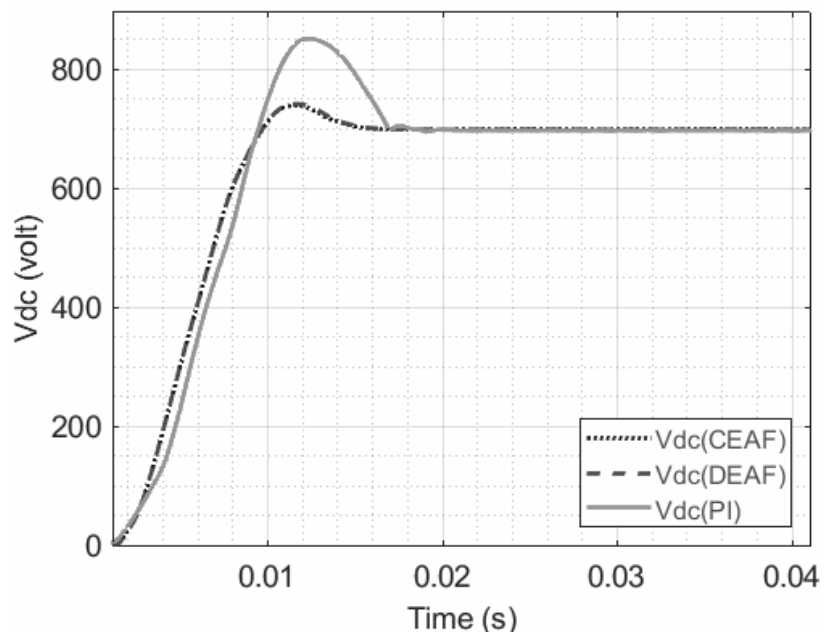

(a)

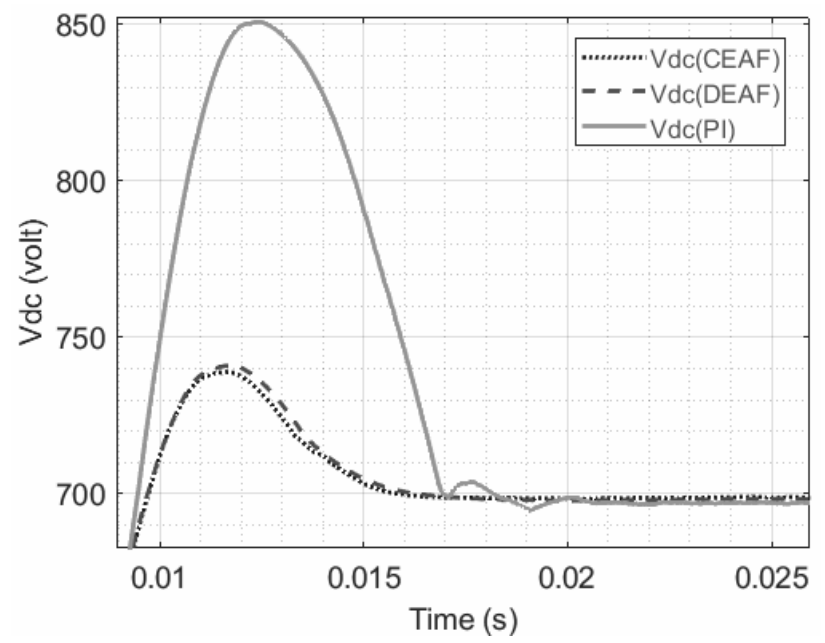

(b)

Figure. 20 DC output of boost rectifier : (a) transient condition, (b)zoomed transient condition

during the boost rectifier starting. The results obtained under unbalanced network conditions from conventional PI controllers, DEAF and the proposed CEAF are shown in Fig. 20.

The voltage overshoot of DEAF is not significantly different from that of CEAF in the transient condition. As seen in Fig. 20, the overshoot is 740 volts. It is $5.71 \%$ higher than the reference voltage, which is 700 volts. On the other hand, the voltage overshoot of the PI controller is 850 volts, which is $21.43 \%$ higher than the reference voltage.

The settling time of DEAF and CEAF is shorter than that of PI controller. Each of DEAF and CEAF controllers needs $0.017 \mathrm{~s}$ to reach the steady-state condition, whereas the PI controller needs $0.021 \mathrm{~s}$.

\section{B. Dynamic Response}

Fig. 21 and 22 display dynamic responses when the DG output changes in each phase to three

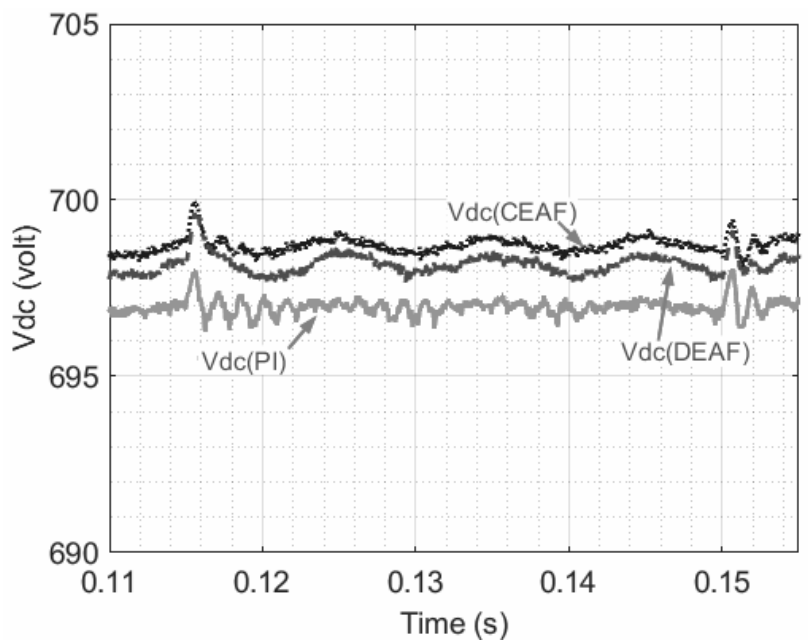

Figure. $21 \mathrm{DC}$ voltage of boost rectifier on the dynamic condition under fluctuating DG and unbalanced AC source

methods. The DC voltage performance of the proposed method is much lower than the other two methods, even in dynamic processes. The results demonstrate the effectiveness of the proposed method in terms of steady-state response and dynamic processes.

Fig. 21 shows some of the dynamic responses. The initial response to the current changes that occur each phase from the steady-state. Phase C experiences an increase in current in the 0.115 second due to $4 \mathrm{~kW}$ injection by DG.

When the reference DC voltage changes from 700 volts to 800 volts, as shown in Fig. 22, each of the controllers needs 0.01 seconds to reach a steady-state condition. A drawback of CEAF controllers is its high overshoot relative to DEAF controllers. As shown in Fig. 22, the highest overshoot of 820 volts occurs when the CEAF is used in the system, whereas the overshoot in the case of DEAF and PI is 813 volts and 801 volts, respectively. Thus, the CEAF overshoot is at least seven volts higher than that of DEAF and PI.

\section{Steady-state Condition}

The results obtained under unbalanced network conditions from conventional PI controllers, DEAF and the proposed CEAF are shown in Figs. 5 and 6. The network's voltage and the current difference is $60 \%$ with a 700 Volts reference output voltage.

Table 6 shows the comparison of the DC voltages as well as the ripples and steady-state errors of three control methods, namely PI, CEAF, and DEAF under unbalanced conditions.

The simulation results of boost rectifiers equipped with each type of controller (CEAF, DEAF, 
and PI) over transient and steady-state conditions period are shown in Fig 24.

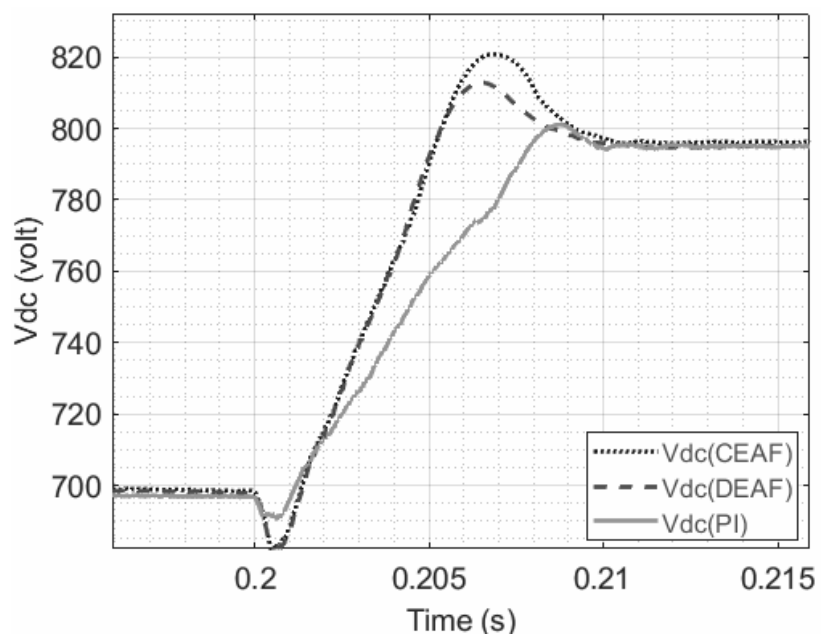

(a)

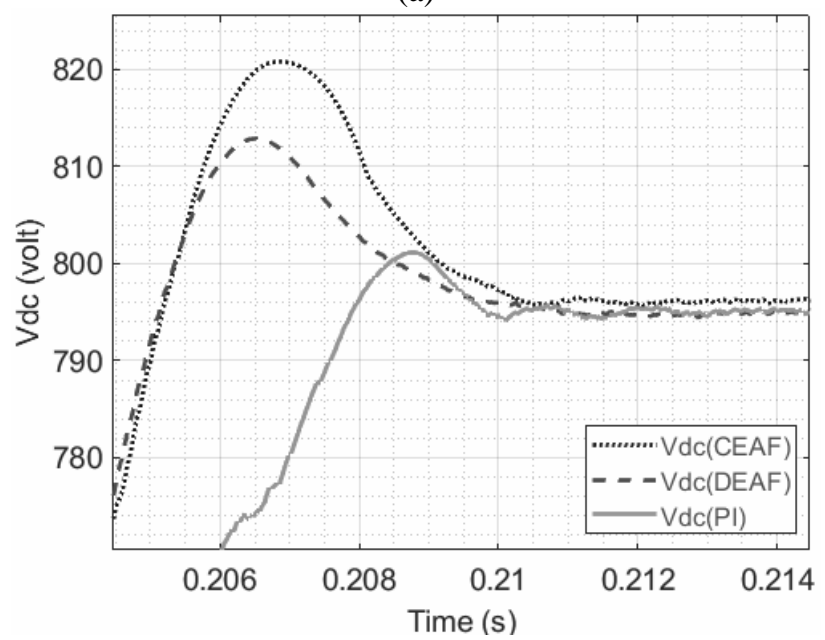

(b)

Figure. 22 DC voltage of boost rectifier on the dynamic condition under increased DC reference of 800 volts and unbalanced $\mathrm{AC}$ sources

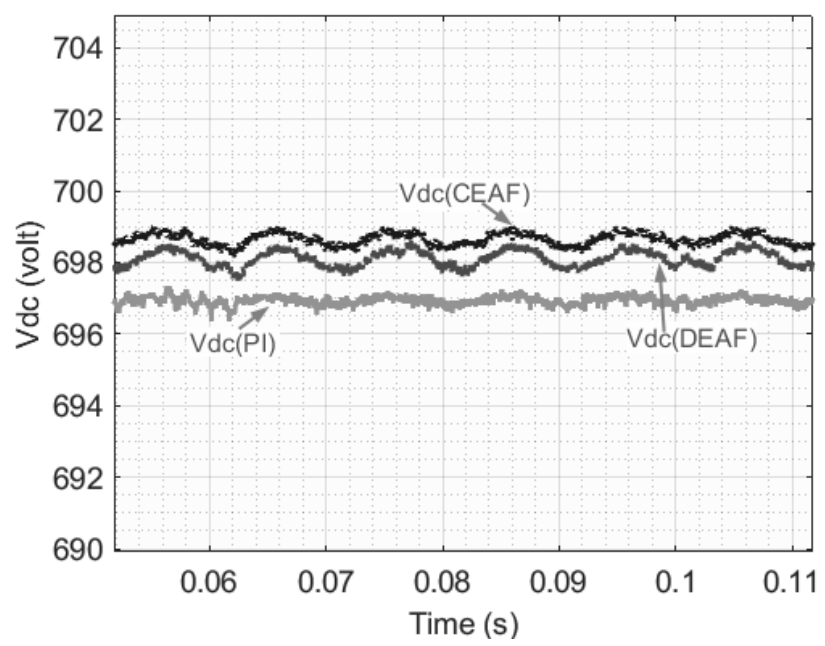

Figure. 23 DC voltage of boost rectifier on steady-state condition

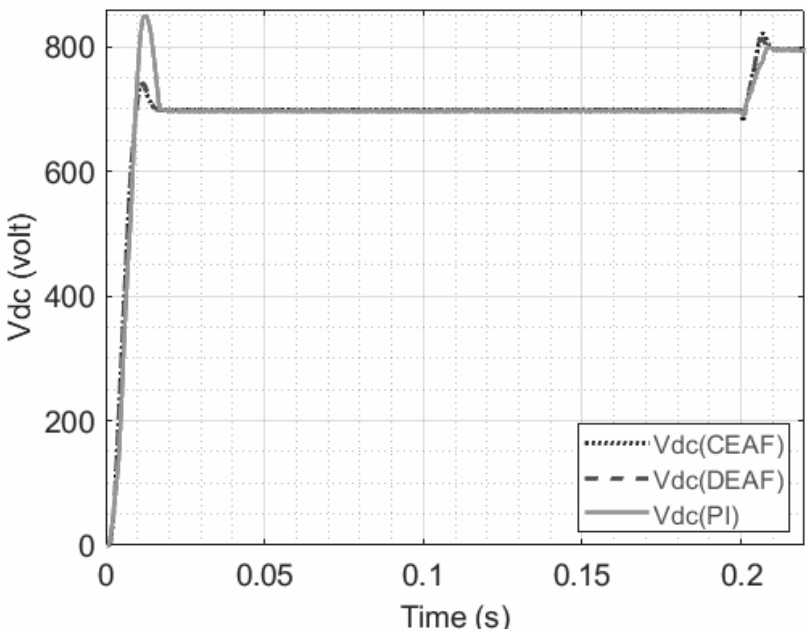

Figure. 24 DC voltage of boost rectifier based on fluctuating DG scenario

Table 6. DC voltage under unbalanced condition

\begin{tabular}{|l|l|l|l|l|c|}
\hline \multirow{2}{*}{} & \multicolumn{3}{|c|}{ Voltage (volt) } & \multirow{2}{*}{ Ripple } & \begin{tabular}{c} 
Steady- \\
state \\
error \\
\cline { 2 - 4 }
\end{tabular} \\
\cline { 2 - 5 } & $\max$ & min & mean & & \\
\hline PI & 696.34 & 697.34 & 696.93 & 0.14 & 0.44 \\
\hline DEAF & 697.48 & 698.62 & 698.1 & 0.16 & 0.27 \\
\hline CEAF & 698.15 & 699.01 & 698.65 & 0.12 & 0.19 \\
\hline
\end{tabular}

The simulation results of the boost rectifiers equipped with PI, DEAF, and CEAF controllers show that the use of CEAF produced the lowest ripple voltage, which was $0.12 \%$. It was 0.04 percentage point decrease compared to the produced ripples in DEAF case. The response time in CEAF case was shorter than that in DEAF case by 0.08 percentage point. These results imply that CEAF controllers are more effective and more accurate than DEAF and PI controllers for boost-rectifiers. The difference is due to differences in each controller's characteristics.

The CEAF controller has the most advantages compared to other types of controllers. It can adapt to both the balanced and fluctuating unbalanced system, so it is able to follow the changes faster with minimum ripple voltage and smaller steady-state error.

\section{Conclusions}

In this study, we show that the optimization method of the adaptive fuzzy-PI controller system is successfully implemented to boost rectifiers. The simulation of three different controllers, namely PI, DEAF, and CEAF, has been carried out at both a balanced and fluctuating unbalanced weak distribution system. The results show that, in comparison with PI and DEAF, the CEAF produces the smallest steady-state error and lowest ripple voltages of the DC voltage. CEAF reduces the 
steady-state error from $0.28 \%$ to become $0.21 \%$ when the Distributed Generation (DG) system is in a balanced condition, and from $0.27 \%$ to become $0.19 \%$ when the DG system is fluctuating and unbalanced. As for the ripple voltages, CEAF reduces them 0.04 percentage points to become $0.12 \%$ when the DG system is fluctuating and unbalanced.

In this research, future work will concentrate on using the proposed method to implement a boost rectifier as a DC source inverter to solve unbalanced problems in the DG system.

\section{Notations}

$\begin{array}{ll}D G & \text { Distributed generation } \\ V_{d c} & \text { DC voltage } \\ v_{a n}, v_{b n}, v_{c n} & \begin{array}{l}\text { phase to netral AC voltage of three } \\ \text { phase system }\end{array} \\ i_{a}, i_{b}, i_{c} & \text { AC source current for each phase } \\ v_{d}, v_{q} & \text { source voltage in dq reference frame } \\ i_{d}, i_{q} & \text { source current in dq reference frame } \\ B & \text { modulation signal } \\ R_{v} & \text { ripple ratio } \\ X_{p} & \text { DEAF output of the CEAF } \\ X_{i} & \text { AEAF output of the CEAF } \\ L R_{a} & \text { learning rate constant of DEAF for } \\ & K_{p}(\mathrm{a}=1,3,5) \\ L R_{b} & \text { learning rate constant of AEAF for } \\ & K_{i}(\mathrm{a}=2,4,6)\end{array}$

\section{References}

[1] C. J. Gajanayake, R. Teodorescu, F. Blaabjerg, D. M. Vilathgamuwa, and P. C. Loh, "Four-leg parallel Z-source inverter based DG systems to enhance the grid performance under unbalanced conditions", In: Proc. of European Conference on Power Electronics and Applications, pp. 110, 2007.

[2] T. Ackermann, G. Andersson, and L. Söder, "Distributed power generation in a deregulated market environment", Electric Power Systems Research, Vol. 57, No. 3, pp. 195-204, 2001.

[3] F. Blaabjerg, R. Teodorescu, M. Liserre, and A. V. Timbus, "Overview of Control and Grid Synchronization for Distributed Power Generation Systems", IEEE Transactions on Industrial Electronics, Vol. 53, No. 5, pp. 13981409, 2006.

[4] Y. Kumsuwan, W. Srirattanawichaikul, S. Premrudeepreechacharn, K. Higuchi, and H. A. Toliyat, "A carrier-based unbalanced PWM method for four-leg voltage source inverter fed asymmetrical two-phase induction motor", In: Proc. of the 2010 International Power Electronics Conference - ECCE ASIA -, pp. 2469-2476, 2010.

[5] Y. Zhang, J. Jiao, J. Liu, and J. Gao, "Direct Power Control of PWM Rectifier With Feedforward Compensation of DC-Bus Voltage Ripple Under Unbalanced Grid Conditions", IEEE Transactions on Industry Applications, Vol. 55, No. 3, pp. 2890-2901, 2019.

[6] D. K. Setiawan, M. Ashari, and M. H. Purnomo, "Diagonal Recurrent Neural Network Control of Four-Leg Inverter for Hybrid Power System Under Fluctuating Unbalanced Loads", In: Proc. of The Third International Student Conference on Advance Science and Technology (ICAST), pp. 11-12, 2009.

[7] D. K. Setiawan, Y. Megantara, and B. N. Syah, "Three phase inverter of UPS control system for harmonic compensator and power factor correction using modified synchronous reference frame", In: Proc. of International Electronics Symposium (IES), pp. 15-19, 2015.

[8] D. K. Setiawan, H. Suryoatmojo, and M. Ashari, "Four-leg Voltage Source Inverter for Voltage and Current Balancing of Distribution Transformer with Distributed Generations", In: Proc. of International Seminar on Intelligent Technology and Its Applications (ISITIA), pp. 93-98, 2018.

[9] P. Joseph and J. Mathew, "Review of current control strategies for a vector controlled three phase UPF rectifier", In: Proc. of International Conference on Power, Instrumentation, Control and Computing (PICC), pp. 1-7, 2015

[10] J. Dannehl and F. W. Fuchs, "Flatness-based voltage-oriented control of three-phase PWM rectifiers", In: Proc. of the 13th International Power Electronics and Motion Control Conference, pp. 444-450, 2008.

[11] Y. Zhang, C. Qu, and J. Gao, "Performance Improvement of Direct Power Control of PWM Rectifier Under Unbalanced Network", IEEE Transactions on Power Electronics, Vol. 32, No. 3, pp. 2319-2328, 2017.

[12] J. Dannehl, C. Wessels, and F. W. Fuchs, "Limitations of Voltage-Oriented PI Current Control of Grid-Connected PWM Rectifiers With LCL Filters", IEEE Transactions on Industrial Electronics, Vol. 56, No. 2, pp. 380388, 2009.

[13] Y. Zhang, Q. Zhang, Z. Li, and Y. Zhang, "Comparative study of model predictive current control and voltage oriented control for PWM rectifiers", In: Proc. of International Conference 
on Electrical Machines and Systems (ICEMS), pp. 2207-2212, 2013.

[14] M. Malinowski and M. Kazmierkowski, "Simple Direct Power Control of Three-Phase PWM Rectifier Using Space Vector Modulation - A Comparative Study", EPE Journal, Vol. 13, no. 2, pp. 28-34, 2003.

[15] H.-S. Song and K. Nam, "Dual current control scheme for PWM converter under unbalanced input voltage conditions", IEEE Transactions on Industrial Electronics, Vol. 46, No. 5, pp. 953959, 1999.

[16] M. P. Kazmierkowski, R. Krishnan, and F. Blaabjerg, Control in Power Electronics: Selected Problems. Academic Press (Elsevier), New York, 2002.

[17] A. Bechouche, H. Seddiki, D. O. Abdeslam, and M. Koussaila, "Adaptive ac filter parameters identification for voltage-oriented control of three-phase voltage-source rectifiers", International Journal of Modelling, Identification and Control, Vol. 24, p. 319, 2015.

[18] A. Prodic, J. Chen, D. Maksimovic, and R. W. Erickson, "Self-tuning digitally controlled lowharmonic rectifier having fast dynamic response", IEEE Transactions on Power Electronics, Vol. 18, No. 1, pp. 420-428, 2003.

[19] Z. Wang and T. Ahn, "Design of the Optimal Self-tuning Fuzzy-PI Controller for Rectifier Current Control in HVDC System", In: Proc. of Chinese Control Conference, pp. 1224-1227, 2006.

[20] R. P. Burgos, E. P. Wiechmann, and J. R. Rodriguez, "An adaptive fuzzy logic controller for three-phase PWM boost rectifiers: design and evaluation under transient conditions", In: Proc. of the 24th Annual Conference of the IEEE Industrial Electronics Society (Cat. No.98CH36200), Vol. 2, pp. 761-767, 1998.

[21] H. Abdel-Maksoud, M. Khater, and S. Shaaban, "Adaptive Fuzzy Logic PI Control for Switched Reluctance Motor Based on Inductance Model", International Journal of Intelligent Engineering and Systems, Vol. 10, No. 4, pp. 41-49, 2017.

[22] C. Conker and M. K. Baltacioglu, "Fuzzy selfadaptive PID control technique for driving $\mathrm{HHO}$ dry cell systems", International Journal of Hydrogen Energy, (In press) 2020. doi: 10.1016/j.ijhydene.2020.01.136

[23] S.-K. Chung, "Phase-locked loop for gridconnected three-phase power conversion systems", In: IEE Proceedings - Electric Power Applications, Vol. 147, No. 3, pp. 213-219, 2000.
[24] D. Dong, B. Wen, D. Boroyevich, P. Mattavelli, and Y. Xue, "Analysis of Phase-Locked Loop Low-Frequency Stability in Three-Phase GridConnected Power Converters Considering Impedance Interactions", IEEE Transactions on Industrial Electronics, Vol. 62, No. 1, pp. 310 321, 2015.

[25] X. Cao, Q.-C. Zhong, and W.-L. Ming, "Ripple Eliminator to Smooth DC-Bus Voltage and Reduce the Total Capacitance Required", IEEE Transactions on Industrial Electronics, Vol. 62, No. 4, pp. 2224-2235, 2015.

[26] M. T. Benchouia, I. Ghadbane, A. Golea, K. Srairi, and M. E. H. Benbouzid, "Implementation of adaptive fuzzy logic and PI controllers to regulate the DC bus voltage of shunt active power filter", Applied Soft Computing, Vol. 28, pp. 125-131, 2015.

[27] K. Y. Ahmed, N. Z. Yahaya, V. S. Asirvadam, K. Ramani, and O. Ibrahim, "Comparison of fuzzy logic control and PI control for a threelevel rectifier based on voltage oriented control", In: Proc. of IEEE International Conference on Power and Energy (PECon), pp. 127-132, 2016.

[28] A. S. Wardhana, M. Ashari, and H. Suryoatmojo, "Optimal Control of Robotic Arm System to Improve Flux Distribution on Dual Parabola Dish Concentrator", International Journal of Intelligent Engineering and Systems, Vol. 13, No. 1, pp. 364-378, 2019. 